\title{
EFFECTS OF ENVIRONMENTAL AND CLINICAL INTERFERENTS ON THE HOST CAPTURE EFFICIENCY OF IMMOBILIZED BACTERIOPHAGES
}

\author{
DANIEL V. DIXON, ZEINAB HOSSEINIDOUST, and NATHALIE TUFENKJI*
}

\author{
Department of Chemical Engineering, McGill University,
}

Montreal, Quebec H3A 2B2, Canada

daniel.dixon@mail.mcgill.ca

zeinab.hosseinidoust@mail.mcgill.ca

nathalie.tufenkji@mcgill.ca

${ }^{*}$ Corresponding Author. Phone: (514) 398-2999; Fax: (514) 398-6678; E-mail:

nathalie.tufenkji@mcgill.ca 


\begin{abstract}
Bacteriophage-functionalized surfaces are a new class of advanced functional material and have been demonstrated to be applicable for use as antimicrobial surfaces in medical applications (e.g., indwelling medical devices or wound dressings) or as biosensors for bacterial capture and detection. However, the complex composition of many real life samples (e.g., blood, natural waters, etc.) can potentially interfere with the interaction of phage and its bacterial host, leading to a decline in the efficiency of the phage-functionalized surface. In this study, the bacterial capture efficiency of two model phage-functionalized surfaces was assessed in the presence of potential environmental and biomedical interferents. The two phage-bacteria systems used in this study are PRD1 with Salmonella Typhimurium and T4 with Escherichia coli. The potential interferents tested included: humic and fulvic acids, natural groundwater, colloidal latex microspheres, host extracellular polymeric substances (EPS), albumin, fibrinogen, and human serum. EPS and human serum decreased the host capture efficiency for immobilized PRD1 and T4, and also impaired the infectivity of the non-immobilized (planktonic) phage. Interestingly, humic and fulvic acids reduced the capture efficiency of T4-functionalized surfaces, even though they did not lead to inactivation of the suspended virions. Neither humic nor fulvic acids affected the capture efficiency of PRD1. These findings demonstrate the inadequacy of traditional phage selection methods (i.e., infectivity of suspended phage towards its host in clean buffer) for designing advanced functional materials and further highlight the importance of taking into account the environmental conditions in which the immobilized phage is expected to function.
\end{abstract}

Keywords: antimicrobial surface, bacteriophage, interferent, advanced functional material, bioactive surface 


\section{INTRODUCTION}

Bacteriophages, viruses that infect bacteria, have attracted considerable attention in the past years as an alternative solution for the control of bacterial populations. This interest has been further fueled by the global crisis over antibiotic resistance. Bacteriophages (phage) offer many advantages over antibiotics and many other common biocides; namely, they can be very specific to their target host, even to the level of a specific subspecies, and are harmless to eukaryotic cells (such as human cells).

Bacteriophages can be immobilized on various substrates for the design of bioactive surfaces. These surfaces have many potential applications such as indwelling medical devices, ${ }^{1,2,3}$ food packagings, ${ }^{4}$ and water filtration systems. ${ }^{5}$ Furthermore, phage-functionalized surfaces can be used in biosensor designs using platforms such as surface plasmon resonance, ${ }^{6,7}$ quartz crystal microbalance, ${ }^{8}$ or dip-stick assays. ${ }^{9}$

In an earlier study, we demonstrated the efficacy of a phage-functionalized surface for the capture and deactivation of bacteria. ${ }^{10}$ The findings emphasized how the orientation of the immobilized phage, specifically the position of its host binding proteins on the surface, played a significant role in the capture of host bacteria. ${ }^{10}$ To extend this work, the efficiency of phage-functionalized surfaces needs to be determined when applied outside of ideal laboratory conditions. Phage-functionalized substrates are expected to remain functional (i.e., able to capture and/or destroy host bacteria) when used in the presence of complex analytes such as those found in wastewater, groundwater or medical samples (e.g., blood or urine). Regardless of the method of immobilization, or the substrate used, the environment that the immobilized phage encounters is expected to significantly affect the phage interaction with its host bacterium, consequently affecting 
the efficiency of the bioactive surface. The conditions encountered by a bioactive surface functionalized with phage may be different from the environment the phage was originally isolated from. Therefore, it is important to study how various biomolecules, particulate matter, natural colloids, or even cells found in such complex environments can affect the efficiency of phage functionalized surfaces.

Much of the research in this area has focused on the effect of environmental conditions on phage attachment to a substrate, ${ }^{11,12,13,14,15,16}$ or on infectivity of nonimmobilized (suspended) phage towards its host. ${ }^{17,} 18$ To our knowledge, there is no report on how environmental conditions may affect the interactions of surfaceimmobilized phage with its host. To address this gap in knowledge, a number of select interferents of relevance to environmental or clinical applications were chosen. The potential interfering molecules/particles were chosen based on potential applications for the phage-functionalized substrate. For example, extracellular polymeric substances (EPS), a mixture of biomolecules secreted by bacteria, are of interest when considering the development of a biofilm-resistant surface. Natural organic fulvic and humic acids are ubiquitous in environmental water samples and should be considered in biosensing or water treatment applications of phage-functionalized surfaces. Larger colloidal particles also present in aquatic environments or biomedical fluids (e.g., blood cells) may interfere with the activity of nano-sized phage. If applications for indwelling medical devices are desired, the immobilized phage must be resilient to the potential effects of serum and blood clotting factors. Two phage/host systems were used herein; namely, PRD1 with Salmonella Typhimurium and T4 with Escherichia coli. The two chosen phages have very different shapes and modes of infection. T4 is an asymmetric tailed phage and is 
representative of $>95 \%$ of known bacteriophages. PRD1 is an icosahedral phage and is completely symmetrical in terms of shape and location of its capture proteins. This study examines the effect of the chosen interferents on the infectivity of non-immobilized (suspended) phage and on the host capture efficiency of the same phages when covalently immobilized on a surface.

\section{Materials AND Methods}

REAGENTS AND MATERIALS

The following chemicals were purchased and used without further purification: agar, ethanol, hydrochloric acid, magnesium sulphate heptahydrate, methanol, sodium hydroxide, sodium chloride, tris(hydroxymethyl)aminomethane, trypticase soy agar, and trypticase soy broth (TSB) (Fisher Scientific). (3-aminopropyl)triethoxysilane (APTES), N-(3-Dimethylaminopropyl)-N'-ethylcarbodiimide hydrochloride (EDC), formaldehyde, N-Hydroxysuccinimide (NHS), bovine serum albumin (BSA), human serum albumin (HSA), human sera, fibrinogen, poly(ethylene glycol), and sulphuric acid (SigmaAldrich). Suwannee River humic acid (SRHA) and Suwannee River fulvic acid (SRFA) were obtained from the International Humic Substances Society. Sulphate latex microspheres $(1 \mu \mathrm{m})$ and SYTO 9 green nucleic acid stain were purchased from Invitrogen. A sample of natural groundwater was collected and characterized as described by Petosa et al. ${ }^{19}$

\section{BACTERIA CULTURE AND BACTERIOPHAGE PROPAGATION}

Salmonella enterica serotype Typhimurium LT2 (HER1023) and bacteriophages PRD1 (HER23) and T4 (HER27) were obtained from the Félix D’Hérelle Reference Centre for Bacterial Viruses (Université Laval, Québec, Canada). Escherichia coli BL21 
(ATCC BAA-1025) was purchased from Cedarlane (Cedarlane Corporation, Burlington, Ontario, Canada).

To prepare the bacterial culture, an inoculum from a frozen glycerol stock $\left(-80^{\circ} \mathrm{C}\right)$ was streaked on a trypticase soy agar (TSA) plate and incubated overnight at $37^{\circ} \mathrm{C}$. A single colony from the plate was used to inoculate $10 \mathrm{~mL}$ of TSB which was incubated overnight $\left(37^{\circ} \mathrm{C}, 150 \mathrm{rpm}\right)$. A $75 \mu \mathrm{L}$ aliquot was taken from the overnight culture and diluted 100 fold into fresh TSB and incubated until a bacterial concentration of $10^{9}$ $\mathrm{CFU} / \mathrm{mL}$ was reached.

Bacteriophage propagation was performed using the soft-agar overlay technique. ${ }^{20}$ Bacteriophages were purified by PEG precipitation ${ }^{21}$ followed by centrifuge filtration (Millipore $100 \mathrm{kDa}$ centrifugal filter unit). Final phage concentrations were adjusted to $10^{11}$ plaque forming units (pfu)/mL in saline-magnesium buffer (SM buffer: $50 \mathrm{mM}$ Tris- $\mathrm{HCl}, 100 \mathrm{mM} \mathrm{NaCl}, 8.1 \mathrm{mM} \mathrm{MgSO} 4, \mathrm{pH} 7.5)$.

\section{EPS EXTRACTION}

Extracellular polymeric substances (EPS) of host bacterium were extracted by the formaldehyde- $\mathrm{NaOH}$ method. ${ }^{22}$ Formaldehyde was added to $10 \mathrm{~mL}$ of bacterial culture to a final concentration of $0.22 \%(\mathrm{v} / \mathrm{v})$. The suspension was then incubated at $4^{\circ} \mathrm{C}$ for $1 \mathrm{hr}$ followed by the addition of $4 \mathrm{~mL}$ of $1 \mathrm{M} \mathrm{NaOH}$. The suspension was incubated at $4{ }^{\circ} \mathrm{C}$ for $3 \mathrm{hrs}$ and then centrifuged at $20,000 \times \mathrm{g}$. After centrifugation, a $0.2 \mu \mathrm{m}$ Millipore membrane filter was used to filter out larger particles and bacteria, and smaller molecules were separated by dialyzing against 1 L DI water with 3500 Da Slide-A-Lyzer dialysis membrane cassette (Thermo Scientific) at $4^{\circ} \mathrm{C}$ for $24 \mathrm{hrs}$. The purified EPS was then 
freeze dried for $24 \mathrm{hrs}$ and the powder was used to prepare known concentrations of EPS solution.

\section{BACTERIOPHAGE INACTIVATION ASSAY}

Bacteriophage inactivation (for non-immobilized or suspended bacteriophage) in the presence of environmental molecules was assessed as described by Kropinski. ${ }^{23}$ Serial dilutions of the potential interferents were made in SM buffer followed by the addition of a known concentration of phage. The phage-interferent suspension was then incubated at room temperature for $1 \mathrm{hr}$. The suspensions were mixed with bacterial host and plated using the soft-agar overlay technique to determine the number of pfu formed. A control sample of phage mixed with only SM buffer without any potential interfering compounds was used to normalize the data.

\section{PREPARATION OF PHAGE-FUNCTIONALIZED SURFACES}

Glass slides coated with aminosilane were prepared as a model substrate for bacteriophage functionalization as described by Hosseinidoust et al. ${ }^{10}$ Briefly, glass discs (12 mm diameter) were sonicated consecutively in $\mathrm{MeOH}: \mathrm{HCl}(1: 1)$ and concentrated $\mathrm{H}_{2} \mathrm{SO}_{4}$. The glass discs were then washed with $\mathrm{EtOH}$ and dried under high purity $\mathrm{N}_{2}$. The clean glass discs were subsequently dipped in a $10 \%(\mathrm{v} / \mathrm{v})$ solution of APTES in EtOH for $30 \mathrm{~min}$, sonicated in $\mathrm{EtOH}$ for $30 \mathrm{~min}$ and dried for $1 \mathrm{hr}$ at $120^{\circ} \mathrm{C}$. Bacteriophages were cross-linked to the aminosilane surface using (EDC $5 \mathrm{mg} / \mathrm{mL})$ and NHS $(6 \mathrm{mg} / \mathrm{mL})$ to couple carboxyl groups in the phage protein coat to amine groups on the disc surface. The phage-functionalized surface was then washed with SM buffer and blocked with 1 $\mathrm{mg} / \mathrm{mL}$ BSA.

IMMOBILIZED PHAGE CAPTURE EXPERIMENT 
Bacterial suspensions were rinsed 3 times $(3000 \times g, 5 \mathrm{~min})$, followed by resuspension in SM buffer containing the desired concentration of the potential interferent. The bacteriophage-functionalized surfaces were then immersed in the bacterial suspensions and left shaking at $150 \mathrm{rpm}$ for $30 \mathrm{~min}$ after which the suspension was replaced with a buffer solution containing the green fluorescent nucleic acid stain SYTO 9 (excitation/emission $485 \mathrm{~nm} / 498 \mathrm{~nm}$ ) and left shaking at $150 \mathrm{rpm}$ for $15 \mathrm{~min}$, followed by a rinse with SM buffer. Bacteria attached to the surface were imaged using an inverted fluorescence microscope (Olympus IX71, Tokyo, Japan) with a filter set capable of illuminating SYTO9. Images were recorded with an Evolution VF cooled monochrome CCD camera $(1392 \times 1040$ resolution with $4 \times 4$ binning $)$ and analyzed using Image-Pro Plus, version 6.0. At least three discs were analyzed for each condition, and at least 30 images were recorded for each disc. Data for attached cells were analyzed by one-way analysis of variance followed by a post-hoc Tukey multiple comparisons of means. $\mathrm{P}$ values $<0.05$ were considered significant.

\section{ELECTRON MICROSCOPY}

Scanning electron microscopy (SEM) was used to image phage-coated surfaces with or without bacteria. Phage-functionalized surfaces were prepared as described for immobilized phage capture experiments and selected discs were incubated with host bacteria to induce bacterial capture by immobilized phage. The slides were subsequently rinsed with SM buffer and fixed with $2.5 \%(\mathrm{v} / \mathrm{v})$ glutaraldehyde. The slides were then dehydrated with a series of ethanol/water solutions (30\% to $100 \% \mathrm{EtOH})$ followed by a series of amyl acetate/ethanol solutions (25\% to $100 \%$ amyl acetate). The slides were air 
dried and coated with $50 \AA$ of an Au-Pd coating (Hummer VI Au-Pd sputter coater). Samples were examined with a Hitachi SU-8000 Field Emission-STEM (FE-STEM).

\section{RESULTS AND DISCUSSION}

\section{PHAGE ACTIVITY IN SUSPENSION}

Before assessing the bacteria capture efficiency of immobilized phage, experiments were carried out to gain a better understanding on whether the potential interfering agents would influence the infectivity of the phage while in suspension. The two phage-host systems used were PRD1 with $S$. Typhimurium and T4 phage with $E$. coli. Phage activity (infectivity) was evaluated using standard culture-based methods. The number of plaques formed after exposure to the interferents of interest was determined by plaque counts using the soft agar overlay method. Herein, fulvic acid, humic acid and EPS were selected as molecular interferents that may be present in natural water samples. Latex microspheres are often used as model colloids in environmental studies and were used here to examine the effect of a $1 \mu \mathrm{m}$-sized non-biological colloid on phage infectivity. Finally, phage activity was also evaluated for phage suspended in a natural groundwater sample.

Figure 1 presents the phage infectivity data normalized as a percentage to the control group. The presence of fulvic acid, humic acid, groundwater, and latex particles (Figure 1a-d, respectively) did not result in any significant reduction in phage activity for either T4 or PRD1 over the concentration ranges tested. EPS was found to reduce the activity of PRD1 up to $45 \%$ at concentrations over $100 \mathrm{mg} / \mathrm{L}$ (Figure 1e). Various interferents of interest in a biomedical context were also selected to examine their effect on phage infectivity. Fibrinogen and albumin were chosen as these proteins are found in 
significant abundance in blood plasma. Phage activity was also evaluated for phage suspended in human serum as a medium relevant in applications such as wound dressings or indwelling medical devices. The presence of albumin and fibrinogen did not lead to a significant change in phage infectivity (Figure $1 \mathrm{~g}$ and h, respectively). For both PRD1 and T4 phage, a decline in phage infectivity was observed with increasing concentrations of serum (Figure 1f). In the presence of undiluted serum, the infectivity of PRD1 and T4 was reduced by $45 \%$ and $20 \%$, respectively.

It is interesting to note that while albumin and fibrinogen, both major components of blood plasma, had no observed effect on the activity of either phage, serum did reduce phage infectivity. With albumin, the most abundant protein by mass, eliminated as the cause, naturally we can conclude there is another component in the serum that is causing the deactivation. The inactivation of phage by serum has been observed previously for two different T-even phages, where horse serum was believed to cause irreversible deactivation. $^{24}$

The EPS extracted from each host bacterium had a different effect in each phagehost system. In the case of T4, there was a slight reduction in infectivity in the presence of EPS from E. coli, but the extent of inactivation was not significant when compared to the control. In contrast, significant inactivation of PRD1 was observed at high concentrations of EPS from $S$. Typhimurium. The different behaviors of the two phage in the presence of EPS can be explained by recalling the different structures, and mechanisms of binding, that are associated with each phage. The prepared EPS suspensions likely contain some lipopolysaccharides (LPS) and membrane proteins from the host bacteria, ${ }^{25}$ which are good candidates for interacting with the phage in 
suspension. In the case of PRD1, the phage attaches to the host bacterium with its $\mathrm{P} 2$ protein via a receptor on the bacterial membrane. ${ }^{26,27}$ This protein-receptor interaction has a high measured affinity with an irreversible binding process that triggers the injection of DNA into the host. ${ }^{28}$ Thus, the presence of bacterial membrane proteins in the EPS preparations would then give a plausible explanation for the reduced titer of PRD1 in the presence of its host EPS: binding of proteins (present in the EPS mixture) to the PRD1 P2 protein may cause PRD1 to simply release its DNA in suspension instead of infecting a host bacterium. In the case of $\mathrm{T} 4$ binding to $E$. coli $\mathrm{B}$, the process is considered to occur in two steps with the first being the reversible binding of the long fibers to diglucosyl residues on the LPS in the bacterial cell wall. ${ }^{29}$ Only after at least three long fibers have attached will the phage induce a conformational change and become irreversibly bound. ${ }^{29}$ Therefore, due to the reversible nature of the first step in the T4 binding process, the inactivation of T4 by the LPS in the EPS mixture can conceivably be less pronounced than an irreversible binding process would be. The result is only the small reduction in activity that was observed.

Another likely explanation for the different effects of EPS on the infectivity of T4 versus PRD1 phage is the variable affinity of the different EPS molecules for the phages. Binding of different EPS components to the phage surfaces can lead to electrostatic, electrosteric, and/or hydrophobic interactions between the phages and their respective host cells.

\section{BACTERIA CAPTURE ON PHAGE-FUNCTIONALIZED SURFACES}

Surfaces functionalized with phages PRD1 and T4 were prepared as detailed in the Materials and Methods section. Interferents cannot be expected by default to affect 
free and immobilized phage similarly; free phages are able to diffuse through a liquid medium and orient themselves in a manner to facilitate attachment to receptors on the host bacteria and infect the host. In contrast, both diffusion and orientation are inhibited for immobilized phage and it is the bacteria that must approach the phage to be captured. Representative images of bacteria attached to the phage-coated surfaces are shown in Figure 2. A scanning electron micrograph of Salmonella attached to a PRD1functionalized model substrate (glass disc) is depicted in Figure 2a. The electron micrograph clearly indicates the presence of phage on the glass surface. The image is fairly representative of the whole sample and demonstrates high surface coverage with a uniform distribution over the entire surface. Figure $2 b$ shows a fluorescence micrograph of Salmonella attached to the PRD1-functionalized surface, which is representative of fluorescence images obtained during the bacterial capture experiments. The presence of phage on the surface significantly enhanced the number of attached bacteria compared to a similar surface without any phage (Figure $2 \mathrm{c}$ ). The bacteria on the surface were also found to be fairly uniformly distributed, likely an effect of the even distribution of the phage on the surface as well as the random nature of bacterial diffusion toward the phage-functionalized substrate.

Bacteria attachment to the phage-coated surfaces was quantified in the presence of a number of interferents of interest in environmental or biomedical applications. The results are summarized for two systems: PRD1 with $S$. Typhimurium (Figure 3a), and T4 with E. coli (Figure 3b). Both systems were evaluated in the presence of EPS from the respective bacterial host, humic acid, fulvic acid, a $1 \mu \mathrm{m}$ model colloidal polystyrene latex particle, and natural groundwater. The systems were also evaluated against simple 
and complex biological interferents, namely human serum, albumin, and fibrinogen. As a control treatment, bacteria attachment to a phage-functionalized surface was assessed in clean buffer free of any potential interferents. Each condition was also tested with a blank; namely, bacteria attachment was assessed on a surface without any bacteriophage.

It is interesting to note that while humic and fulvic acids did not cause phage inactivation (Figure 1a and b), they did reduce the capture efficiency of immobilized T4 (but not PRD1) by over 60\% in each case (Figure 3). This suggests that humic and fulvic acids may not be damaging phage $\mathrm{T} 4$, but rather preventing bacterial attachment to the immobilized phage. While no published study has reported on the interactions of T4 with humic or fulvic acids, there have been reports on other viruses. Bacteriophage MS2 has been observed to form reversible complexes with fulvic acid, ${ }^{11}$ and poliovirus has been found to interact with humic and fulvic acids. ${ }^{30}$ Thus, it is likely that these organic acids can interact with $\mathrm{T} 4$ in a manner that would interfere with the ability of the $\mathrm{T} 4$ receptors to attach to their host bacteria. The reversibility of this interaction would also explain why no effect was seen when determining suspended phage inactivation when the phage and bacteria were able to diffuse more freely to a favorable binding position.

For both PRD1 and T4, the presence of the host EPS in suspension during bacterial capture on the surface resulted in fewer bacteria attached when compared to the control. Also, a higher concentration of EPS resulted in greater interference in bacterial binding. For PRD1-functionalized surfaces, this corresponded to a $20 \%$ reduction in bacterial capture at $20 \mathrm{mg} / \mathrm{L}$ and a $70 \%$ reduction at $100 \mathrm{mg} / \mathrm{L}$ of EPS. For T4functionalized surfaces, the reduction was $50 \%$ and $80 \%$ compared to the control for the respective EPS concentrations at $20 \mathrm{mg} / \mathrm{L}$ and $100 \mathrm{mg} / \mathrm{L}$. The effect observed with PRD1 
may be explained by the irreversible attachment of EPS proteins to the phage as described in the evaluation of phage inactivation (Figure 1e). The occupied receptors on PRD1 would prevent bacterial attachment. When considering the T4-functionalized surface, a similar mechanism is likely taking place; the LPS in the EPS mixture is likely binding to the phage fibers, thereby blocking the attachment to bacteria. There was a greater effect of EPS on immobilized T4 bacteria capture efficiency (Figure 3b), than there was on T4 inactivation (Figure 1e). This difference may occur because, when suspended, T4 is free to diffuse and favorably interact with its host cell, but when immobilized, the T4 is unable to reorient itself, thereby preventing bacterial attachment.

The presence of a model environmental colloid (latex microsphere) did not interfere with the bacterial capture efficiency of either phage (Figure 3). Likewise, exposure to a natural unfiltered groundwater did not lead to a measurable change in bacterial capture. It has been hypothesized that some tailed phages may be polarized in charge, with the tail fibers exhibiting positive charge and the phage head exhibiting negative charge. ${ }^{31}$ If we accept this notion of polarity, it is expected that the negatively charged latex particles attach to and block the capture proteins on the positively charged tail fibers of T4, affecting its capture efficiency. The lack of such an effect could be interpreted as the absence of this polarity for $\mathrm{T} 4$ or the relative weakness of the positive charge on the tail fibers, such that the electrostatic attraction is overcome by the shear induced by rinsing the phage-functionalized surface.

For both the PRD1/S. Typhimurium and T4/E. coli systems, the presence of serum led to an $85 \%$ and a $70 \%$ reduction in the amount of bacterial attachment to the phage-functionalized surface, respectively. This result is likely related to the direct 
inactivation of the phage, as observed in the phage inactivation assay (Figure 1f). Indeed, a greater extent of bacterial capture interference is noted for PRD1 (Figure 3a), which correspondingly experienced greater inactivation in the presence of serum (Figure 1f): a $45 \%$ reduction in PRD1 activity is observed versus a $20 \%$ reduction for $\mathrm{T} 4$. The presence of fibrinogen or albumin did not lead to a significant reduction in the bacteria capture efficiency of either phage (Figure 3).

In examining the results presented in Figure 3, it appears that the presence of interferents affects the capture efficiency of T4 phage more than PRD1. This could be explained by the difference in shape, mode of infection and molecular composition of the phage capsid for the two phages. T4 and PRD1 have different capture proteins with affinities for different molecules on the bacterial host cell surface. Therefore, certain interferents may bind to one and not the other. Furthermore, PRD1 contains lipids in its protein coat and is thus expected to be relatively hydrophobic whereas T4 is a hydrophilic phage. ${ }^{32}$ The relative hydrophobicity of PRD1 could decrease its interaction with the interferents in the medium ${ }^{33}$, hence explaining the lower effect of interferents on the efficiency of immobilized PRD1. Moreover, T4 is an asymmetric phage that must be immobilized on the surface with its tail fibers oriented away from the surface to capture bacteria. The orientation of the T4 population immobilized on the surface cannot be controlled with conventional methods and hence is a mixture of three possible orientations (tail facing away from the surface, tail attached to the surface and phage lying on the side). ${ }^{10}$ Therefore, a portion of the $\mathrm{T} 4$ population is completely inactive (tail attached to the surface) and another portion has a completely favorable orientation (tail pointing away from the surface). A third subpopulation of the immobilized T4 phage is 
lying sideways on the surface and can still function in capturing bacteria (although with a lower efficiency). The presence of macromolecular interferents in the medium can readily interfere with the, already weak, capture ability of the latter subpopulation of T4 phage by introducing steric hindrance and electrostatic repulsion.

\section{Conclusions}

The efficiency of phage-functionalized surfaces was assessed when subjected to biomolecules/particulate matter found in environmental or biomedical samples for two model bacteriophages, PRD1 and T4. The aim of this study was to determine whether potential applications involving phage-functionalized surfaces would face challenges when used under more complex environmental or biomedical conditions. Overall, PRD1 and T4 performed well, with an exception being in the presence of serum. Serum was found to reduce the activity of both phages and resulted in fewer bacteria attaching to their respective phage-functionalized surfaces. EPS from the host bacterium also diminished the ability for the immobilized phages to capture their hosts. The natural organic materials, humic and fulvic acids, both reduced the capture efficiency of T4 when immobilized, but did not cause any irreversible inactivation. These results demonstrate that environmental and clinical interferents can affect the efficiency of phagefunctionalized bioactive surfaces even if phage infectivity is not affected. Furthermore, this research highlights the need for these bioactive substrates to be tested under conditions relevant to the final application. 


\section{ACKNOWLEDGEMENTS}

The authors acknowledge the Natural Sciences and Engineering Research Council of Canada (NSERC Strategic Research Network on Bioactive Paper-SENTINEL), the Canada Research Chairs (CRC) program, and the EUL fund in the Department of Chemical Engineering at McGill University.

\section{AUTHOR INFORMATION \\ Corresponding Author \\ *E-mail: nathalie.tufenkji@,mcgill.ca}

\section{Notes}

The authors declare no competing financial interest. 


\section{REFERENCES}

1. Curtin, J. J.; Donlan, R. M. Using bacteriophages to reduce formation of catheterassociated biofilms by Staphylococcus epidermidis. Antimicrob Agents Chemother 2006, 50 (4), 1268-75.

2. $\quad$ Fu, W.; Forster, T.; Mayer, O.; Curtin, J. J.; Lehman, S. M.; Donlan, R. M. Bacteriophage cocktail for the prevention of biofilm formation by Pseudomonas aeruginosa on catheters in an in vitro model system. Antimicrob Agents Chemother 2010, 54 (1), 397-404.

3. Carson, L.; Gorman, S. P.; Gilmore, B. F. The use of lytic bacteriophages in the prevention and eradication of biofilms of Proteus mirabilis and Escherichia coli. FEMS Immunol Med Microbiol 2010, 59 (3), 447-55.

4. $\quad$ Anany, H.; Chen, W.; Pelton, R.; Griffiths, M. W. Biocontrol of Listeria monocytogenes and Escherichia coli $\mathrm{O} 157: \mathrm{H} 7$ in meat by using phages immobilized on modified cellulose membranes. Appl Environ Microbiol 2011, 77 (18), 6379-87.

5. $\quad$ Zhang, Y.; Hunt, H. K.; Hu, Z. Application of bacteriophages to selectively remove Pseudomonas aeruginosa in water and wastewater filtration systems. Water Res 2013, 47 (13), 4507-18.

6. $\quad$ Arya, S. K.; Singh, A.; Naidoo, R.; Wu, P.; McDermott, M. T.; Evoy, S. Chemically immobilized T4-bacteriophage for specific Escherichia coli detection using surface plasmon resonance. Analyst 2011, 136 (3), 486-492.

7. Tawil, N.; Sacher, E.; Mandeville, R.; Meunier, M. Surface plasmon resonance detection of E. coli and methicillin-resistant $S$. aureus using bacteriophages. Biosens Bioelectron 2012, 37 (1), 24-29.

8. $\quad$ Guntupalli, R.; Sorokulova, I.; Olsen, E.; Globa, L.; Pustovyy, O.; Moore, T.; Chin, B.; Barbaree, J.; Vodyanoy, V. Detection and identification of methicillin resistant and sensitive strains of Staphylococcus aureus using tandem measurements. J Microbiol Methods 2012, 90 (3), 182-191.

9. $\quad$ Derda, R.; Lockett, M. R.; Tang, S. K.; Fuller, R. C.; Maxwell, E. J.; Breiten, B.; Cuddemi, C. A.; Ozdogan, A.; Whitesides, G. M. Filter-based assay for Escherichia coli in aqueous samples using bacteriophage-based amplification. Anal Chem 2013, 85 (15), 7213-7220. 10. Hosseinidoust, Z.; van de Ven, T. G.; Tufenkji, N. Bacterial capture efficiency and antimicrobial activity of phage-functionalized model surfaces. Langmuir 2011, 27 (9), 5472-80. 11. Bixby, R. L.; O'Brien, D. J. Influence of fulvic acid on bacteriophage adsorption and complexation in soil. Appl Environ Microbiol 1979, 38 (5), 840-5.

12. Thompson, S. S.; Yates, M. V. Bacteriophage inactivation at the air-water-solid interface in dynamic batch systems. Appl Environ Microbiol 1999, 65 (3), 1186-90.

13. Harvey, R. W.; Ryan, J. N. Use of PRD1 bacteriophage in groundwater viral transport, inactivation, and attachment studies. FEMS Microbiol Ecol 2004, 49 (1), 3-16.

14. Foppen, J. W.; Okletey, S.; Schijven, J. F. Effect of goethite coating and humic acid on the transport of bacteriophage PRD1 in columns of saturated sand. J Contam Hydrol 2006, 85 (34), 287-301.

15. Archer, M. J.; Liu, J. L. Bacteriophage T4 Nanoparticles as Materials in Sensor Applications: Variables That Influence Their Organization and Assembly on Surfaces. Sensors 2009, 9 (8), 6298-6311.

16. Pham, M.; Mintz, E. A.; Nguyen, T. H. Deposition kinetics of bacteriophage MS2 to natural organic matter: role of divalent cations. J Colloid Interface Sci 2009, 338 (1), 1-9.

17. Yates, M. V.; Gerba, C. P.; Kelley, L. M. Virus persistence in groundwater. Appl Environ Microbiol 1985, 49 (4), 778-81.

18. Knezevic, P.; Obreht, D.; Curcin, S.; Petrusic, M.; Aleksic, V.; Kostanjsek, R.; Petrovic, O. Phages of Pseudomonas aeruginosa: response to environmental factors and in vitro ability to inhibit bacterial growth and biofilm formation. J Appl Microbiol 2011, 111 (1), 245-54. 
19. Petosa, A. R.; Ohl, C.; Rajput, F.; Tufenkji, N. Mobility of nanosized cerium dioxide and polymeric capsules in quartz and loamy sands saturated with model and natural groundwaters.

Water Res 2013, 47 (15), 5889-5900.

20. $\quad$ Kropinski, A. M.; Mazzocco, A.; Waddell, T. E.; Lingohr, E.; Johnson, R. P.

Enumeration of bacteriophages by double agar overlay plaque assay. Methods Mol Biol 2009, 501, 69-76.

21. Sambrook, J.; Russell, D. W. Molecular cloning: a laboratory manual; 3 ed.; Cold

Spring Harbour laboratory Press: Cold Spring Harbour, NY, 2001.

22. Liu, H.; Fang, H. H. Extraction of extracellular polymeric substances (EPS) of sludges. $J$. Biotechnol. 2002, 95 (3), 249-56.

23. Kropinski, A. M. Measurement of the bacteriophage inactivation kinetics with purified receptors. Methods Mol Biol 2009, 501, 157-160.

24. Jerne, N. K.; Avegno, P. The development of the phage-inactivating properties of serum during the course of specific immunization of an animal: reversible and irreversible inactivation. J Immunol 1956, 76 (3), 200-8.

25. Flemming, H. C.; Wingender, J. The biofilm matrix. Nat Rev Microbiol 2010, 8 (9), 623-

33.

26. Mindich, L.; Bamford, D.; McGraw, T.; Mackenzie, G. Assembly of bacteriophage PRD1: particle formation with wild-type and mutant viruses. $J$ Virol 1982, 44 (3), 1021-30.

27. Kotilainen, M. M.; Grahn, A. M.; Bamford, J. K.; Bamford, D. H. Binding of an

Escherichia coli double-stranded DNA virus PRD1 to a receptor coded by an IncP-type plasmid. J Bacteriol 1993, 175 (10), 3089-95.

28. Grahn, A. M.; Caldentey, J.; Bamford, J. K.; Bamford, D. H. Stable packaging of phage

PRD1 DNA requires adsorption protein $\mathrm{P} 2$, which binds to the IncP plasmid-encoded conjugative transfer complex. J Bacteriol 1999, 181 (21), 6689-96.

29. Goldberg, E.; Grinius, L.; Letellier, L. Recognition, attachment, and injection. In

Molecular biology of bacteriophage T4, Karam, J. D.; Drake, J. W., Eds.; American Society for Microbiology: Washington, DC, 1994, pp 347-346.

30. Sobsey, M. D.; Hickey, A. R. Effects of humic and fulvic acids on poliovirus

concentration from water by microporous filtration. Appl Environ Microbiol 1985, 49 (2), 259-64.

31. Serwer, P. Agarose gel electrophoresis of bacteriophages and related particles. Journal of Chromatography B: Biomedical Sciences and Applications 1987, 418 (C), 345-357.

32. Shields, P. A.; Farrah, S. R. Characterization of virus adsorption by using DEAE-

Sepharose and octyl-Sepharose. Appl. Environ. Microbiol. 2002, 68 (8), 3965-3968.

33. Zhao, C.; Zhao, J.; Li, X.; Wu, J.; Chen, S.; Chen, Q.; Wang, Q.; Gong, X.; Li, L.; Zheng, J. Probing structure-antifouling activity relationships of polyacrylamides and polyacrylates.

Biomaterials 2013, 34 (20), 4714-4724. 

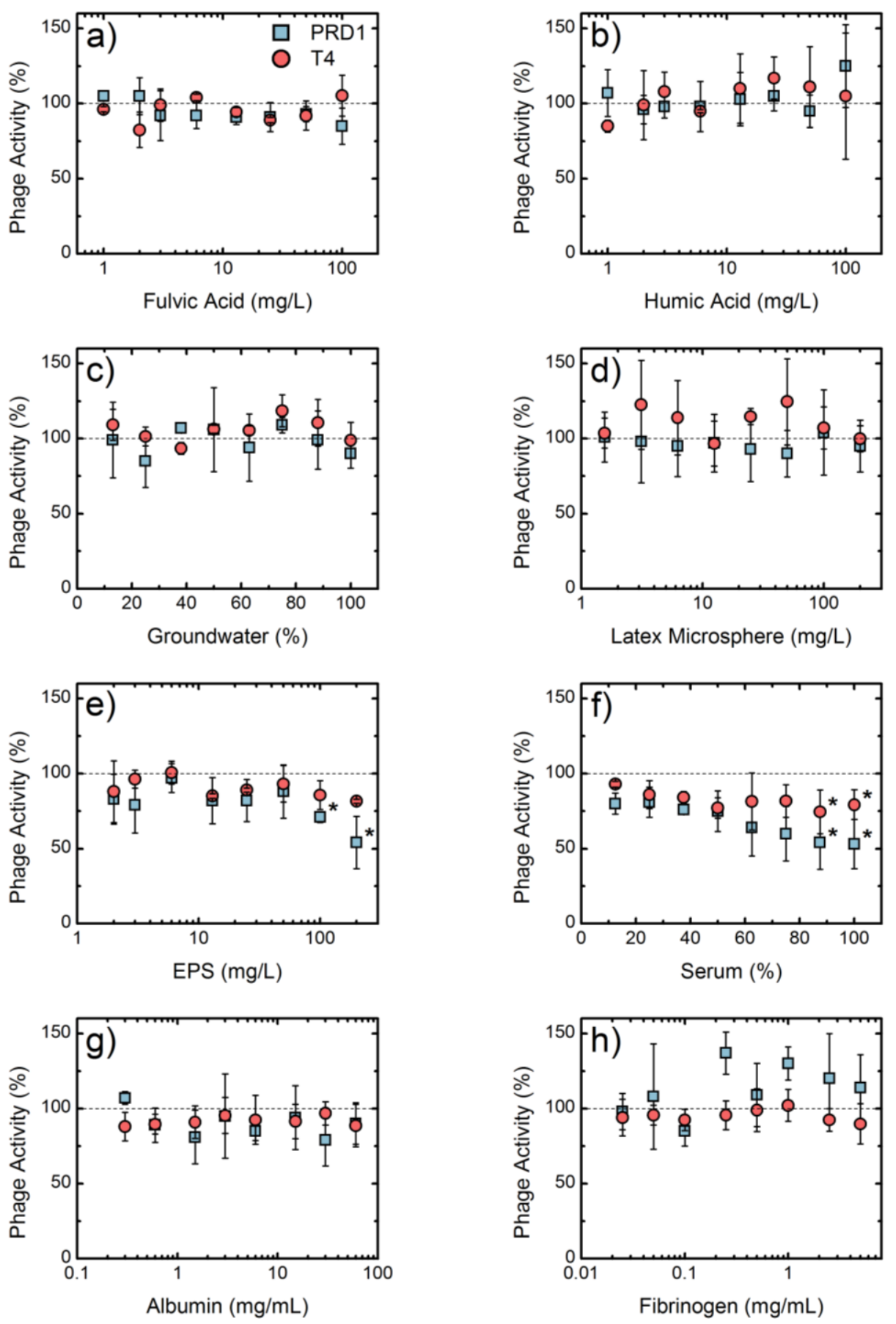

Figure 1. Bacteriophage activity versus concentration of potential interfering substances. PRD1 (circles) and T4 (squares) activity was measured against hosts $S$. Typhimurium and E. coli, respectively. Data represent the mean \pm standard deviation. Data significantly different from the control $(\mathrm{p}<0.05)$ are indicated with *. 

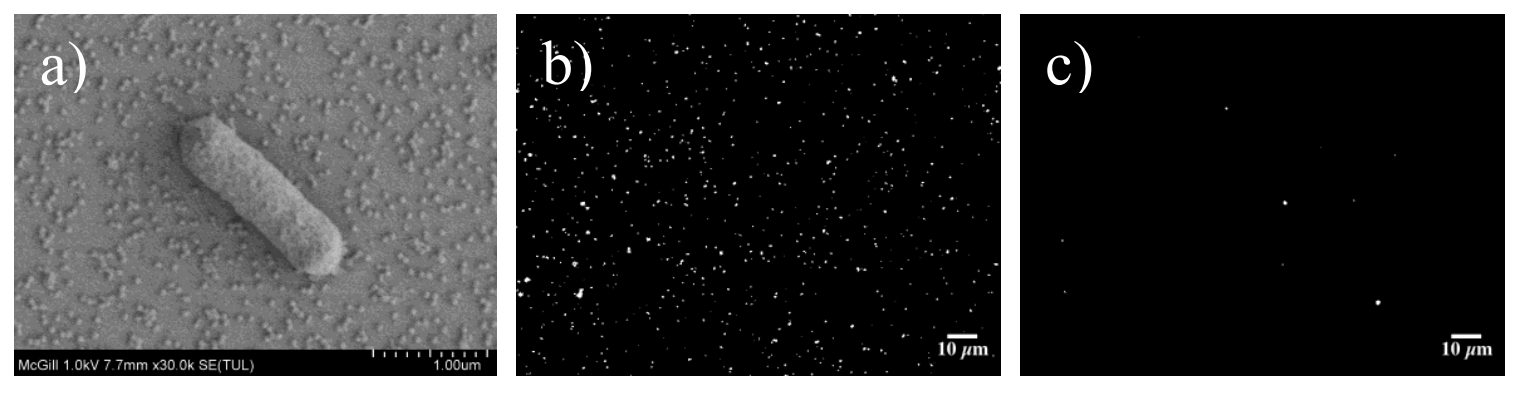

Figure 2. (a) Scanning electron micrograph and, (b) fluorescence micrograph of $S$. Typhimurium attachment to a PRD1-coated model substrate. (c) Fluorescence micrograph of $S$. Typhimurium attachment to a control surface without PRD1. The fluorescence images have been converted to black and white for clarity. The bacteria are shown in white over a black background. 

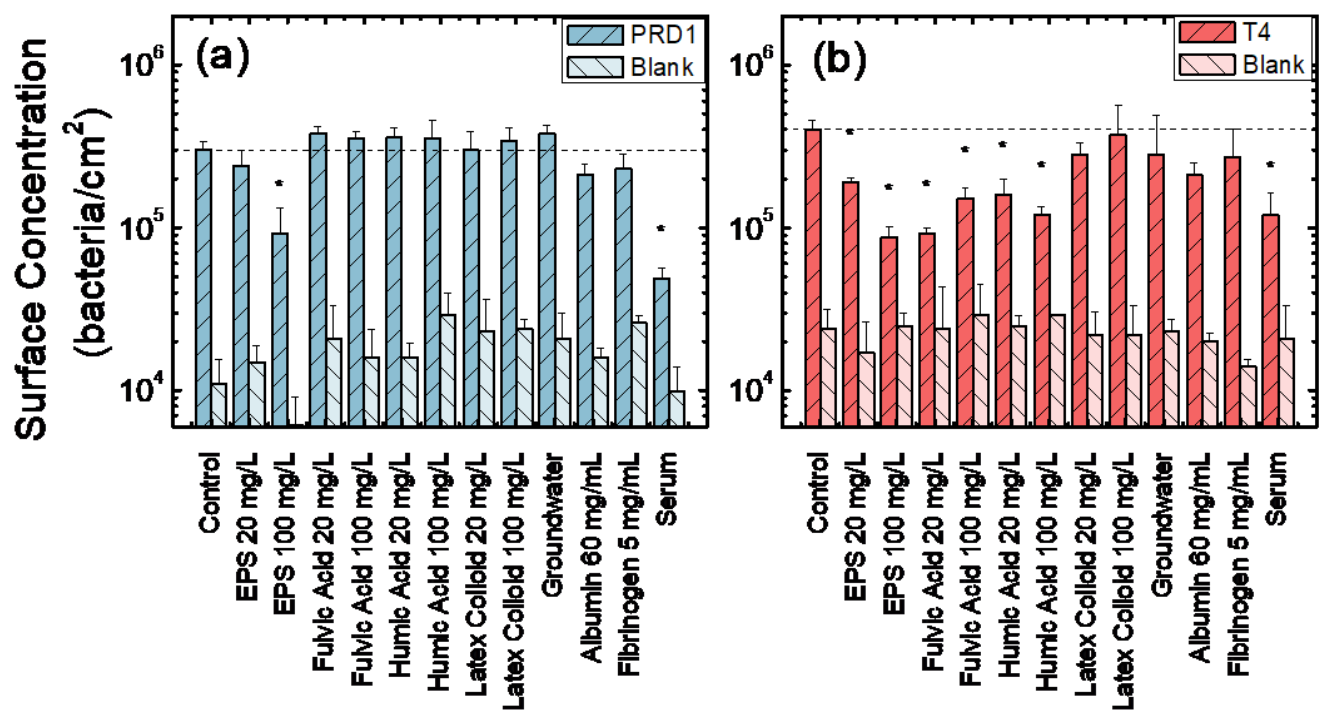

Figure 3. Number of bacteria attached to the covalently immobilized bacteriophage for (a) PRD1 and (b) T4, in the presence or absence of potential interferents of interest. Blanks are the same treatment in the absence of bacteriophage. Data significantly different from the control $(\mathrm{p}<0.05)$ are indicated with $*$. Data represent the mean \pm standard deviation. 


\section{Graphical Abstract}

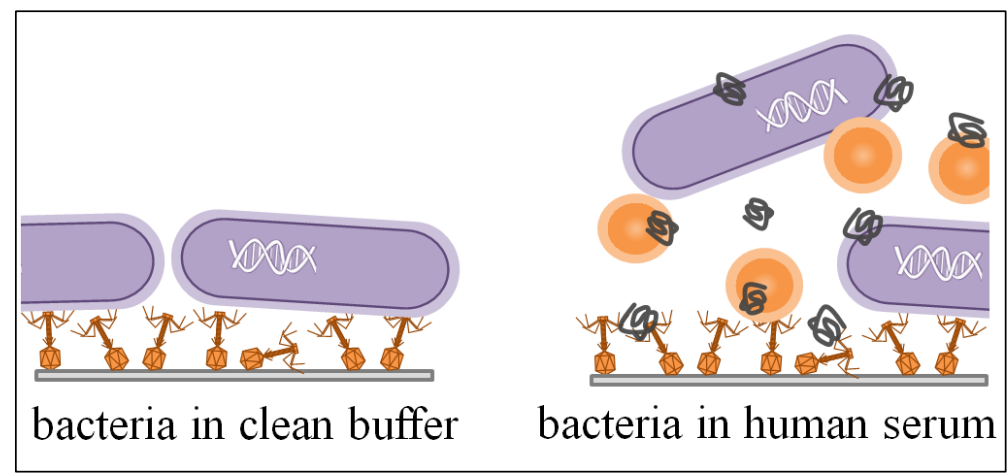

